\title{
AN ANTIBACTERIAL SUBSTANCE FROM SEVERAL STRAINS OF PENICILLIA AND ITS PROBABLE . IDENTITY WITH PENICILLIN
}

\author{
By Hamao UMEZAWA, Tomio TAKEUCHI, Fumiko SHIOZAWA, \\ KENJI UEKANE and ToKU ISHIKAWA. \\ National Institute of Health of Japan, Tokyo.
}

This work has been performed from February 1944 to March 1945 at the Government Institute for Infectious Diseases.

With the news of the remarkable therapeutic effect of penicillin in England and America the Japanese Penicillin Research Committee was organized by many investigators in the fields of medicine, agriculture, botany and chemistry in February 1944. Since that time, as one of the members, we have set about penicillin study. By the cooperation of T. Yabuta, Prof. of the Division of Agricultural Chemistry, Tokyo Imperial University, K. Sakaguchi, Prof. of the other Laboratory of the same Division, T. Tamiya, Prof. of the Division of Hygiene, T. Imp. Univ., and us four strains of penicillia, No. 176, No. 233, No. U-33 and No. H-9, which produce antibacterial súbstances, were isolated after the examination of many molds. Then we began to try to extract the antibacterial substances from 176, 233 and U-33 strains. Since the culture liquid of H-9 was toxic for mice, studies on this strain were abandoned for sometime.

The antibacterial substance of these three strains were extracted with ether at $\mathrm{pH} 2$ and then with phosphate buffer at $\mathrm{pH} 7$, as Raistrick and others ${ }^{(1)}$ described about p.nicillin, and it was observed in September 1944 that this buffer solution was therapeutically active against pneumococcal infection of mice.

Then by co-operation with Prof. Sumio Umezawa, at the Industrial Ch.mical Department of Keio Univdrsity, the active element was purified in October 1944, up to the yellow crystalline powder as its calcium salt which inhibited completely the growth of Staphylococcus aureus (Terajima strain) at the dilution 1:3,200,000 and which showed chemical properties (the elemental analysis and the colour reactions) similar to the results reported by Catch, Cook and Heilbron. (2) This was the first successful purification work of penicillin in Japan.

Details are as follows.

\section{About the strains}

Strains 176 and 233 were isolated by Yabuta, Tamiya and us after the examination of many strains $s_{r}$ preserved in Nagao Institute. According to Kominami, Member of Nagao Institute, the preserved strains of penicillia were occasionally contaminated with the other penicillia and these two were isolated from these contaminations (233 from the contamination inPenicillium expansum).

Strain U-33 was isolated by us after the examination of many molds growing on Endo's plates which had been employed for the examination of dysentery carrier and be laft on the laboratory bench. 
All these three strains produced an anti-staphylococcal substance in Czapeck-Dox medium as Raistrick(1) had described at first, but soon after they: all lost their ability to produce the antibacterial substance in this medium alone, and in order to obtain the antibacterial activity it was necessary to add the yeast extract or peptone. And it was ascertained by Kominami that they all belonged to Penicillium chrysogenum series as Fleming's strain ${ }^{(1)}$.

The other strains, P 1 (isolated by Otsuki, Prof. of the Women's Normal Higher School in Tokyo), Penicillium corylophillum preserved at the Army Medical School and other lately' isolated strains were also studied.

II. Culture media for' production of the antibacterial substance.

1) Modified Czapeck-Dox medium added with dried yeast or peptone.

A.

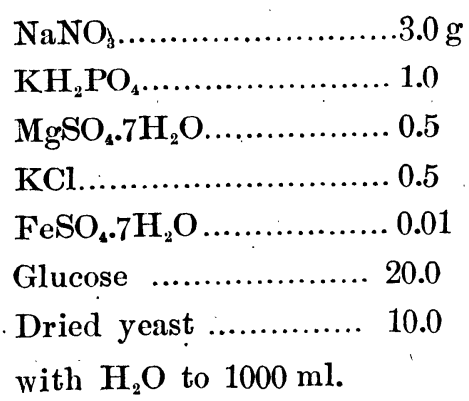

B.

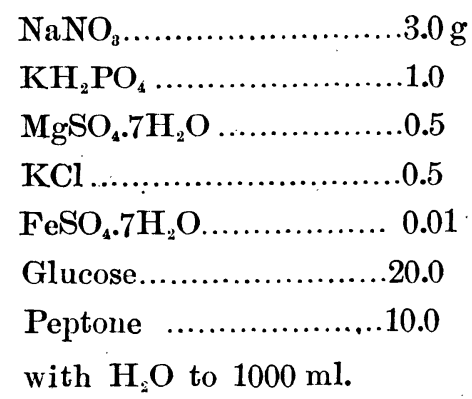

2) Glucose (1\%)-Broth.

3) Peptone..................10 g

Whey $.1000 \mathrm{ml}$.

Whey is the rest of milk after butter and casein taken off.

4) Dried pupa of silk worm.............100 g

Glucose ............................10 g

with $\mathrm{H}_{2} \mathrm{O}$ to $1000 \mathrm{ml}$.

5) Acid hydrolised pupa of silk-worm (2-5\% as dried pupa)

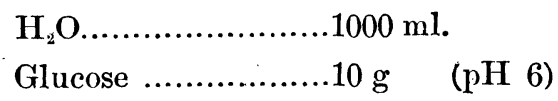

In these media at $20-25^{\circ} \mathrm{C}$ (optimum $23^{\circ} \mathrm{C}$ ) the mold grew on the surface as a fluffy growth changing in a few days to a dark green felted mass and the fluid became bright yellow. 7-10 days after cultivation the fluid proved bacteriostatic and its $\mathrm{pH}$ changed to about 7.0. If it was cultivated at above $25^{\circ} \mathrm{C}$, the fluid became more bright yellow but did not acquire the antibacterial activity. Among these media the antibacterial activity was strongest in the modified Czapeck-Dox medium added with yeast extract or peptone and the fluid inhibited completely the growth of Staphylococcus aureus (Terajima strain) at the dilution $1: 400-800$ (tested by the Fleming's dilution method). The addition of the extract of these molds promoted the penicillin production.

Afterwards, fructose, maltose, saccharose and lactose were tested for the penicillin 
production and it was found that they all were superior to glucose and among them lactose was the best carbohydrate.

\section{Purification of the antibacterial substance.} (in co-operation with Sumio Umezawa).

When the antibacterial activity in the culture fluid reaches its maximum, the liquor under the mold is filtered in a cold room (about $5^{\circ} \mathrm{C}$ ) and cooled to $0^{\circ} \mathrm{C}$. Then phosphoric acid is slowly added until the $\mathrm{pH}$ drops to 2.0 and after shaken with pure high grade ether, the antibacterial substance goes into ether. From thise ther solution it is again extracted with phosphate buffer ( $\mathrm{pH} 7$ ). This procedure is repeated two times and the brown yellow buffer solution which inhibits the growth of Staphylococcus at dilution of 1:10000-100,000 is obtained. Instead of ether, amylacetate can also be used.

As the antibacterial activity in the culture fluid has scarcely diminished by heating at $55^{\circ} \mathrm{C}(\mathrm{pH} 6.5)$ for one hour, it, is convinient to concentrate the fluid to its $1 / 10$ volume by vacuum distillation before the ether extraction, in order to treat the large quantity of the culture fluid. In addition to this vacuum distillation method, the freezing method was also tested. After the culture fluid was frozen and the ice in fluid removed, the culture fluid can be concentrated to about $1 / 3-1 / 5$ of its original volume. In another method, the active element is adsorbed at first from the culture fluid by charcoal (charcoal is added to $1 \%$ usually) aud then eluted with acetone. Then acetone is destilled off in vacuum at about $45^{\circ} \mathrm{C}$ and the brown turbid solution is left. From this residual solution the bright brown yellow solution, highly inhibitorily active, is obtained by etherbuffer extraction. This adsorption method was first applied to the extraction of other antibacterial substances by Hosoya and then applied to penicillin extraction by Yabuta, Hosoya and us.

Then, to remove the contaminating brownish yellow coloured substance the buffer solution of the autibacterial substance is extracted at $\mathrm{pH} 5$ with chloroform. The brown substance goes into chloroform and the antibacterial activity is left in the buffer solution. The buffer solution is again extracted with ether at $\mathrm{pH} 2$ and $0^{\circ} \mathrm{C}$, and this ether solution is shaken with water suspension of barium carbonate, then the active element goes into the water layer. The water solution is filtered and the filtrate is dried, and the crystalline yellow coloured powder of the antibacterial substance as its barium salt is obtained.

By using calcium carbonate in place of barium carbonate calcium salt of the antibacterial substance is also obtained. The most active powder from 176 strain inhibited the growth of Staphylococcus Terajima strain, at the dilution $1: 6400,000$ and those from 233 and $U-33$ at the dilution $1: 1,600,000$. But during dryiug the antibacterial activity was seriously damaged, so the powder from 176 strain inhibited usually Terajima strain at $1: 3,200,000$ and that from $U-33$ at $1: 1000,000$. 'This barium carbonate or calcium carbonate method was found by S. Umezawa and us in October, 1944.

IV. Some chemical properties of the antibacterial substance(in co-operation with Sumio Umezawa).

The result of the elemental analysis of the barium salt conformed to $\mathrm{C}_{24} \mathrm{H}_{33} \mathrm{O}_{11} \mathrm{NBa}$ 
and the absorption maximum of free acid of the antibacterial substance (preparations from 176, 233, U-33, P I and $P$. coryllophylum) existed at about 2750A. This active substance loses its activity by treating it with very weak alkali $\left(1 / 20-\mathrm{N} \mathrm{Ba}(\mathrm{OH})_{2}\right)$, and the elemental analysis of this decomposed substance showed $\mathrm{C}_{11} \mathrm{H}_{28} \mathrm{O}_{12} \mathrm{Ba}$. That is, nitrogene in the antibacterial substance seemed to be very easily removed by weak alkali.

The sodium and ammoniac salt were soluble in water, acetone, methyl-alcohol, and buthanol, and the calcium salt slightly soluble in methyl-alcohol. They were all insoluble in ether, chloroform and petroleum ether. Their free acid was soluble in ether,

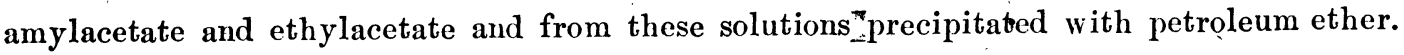

V. Some bacterilogical studies on the antibacterial substance.

This substance was highly bacteriostatic against Staphylococcus, Pneumococcus, Streptococcus hemolyticus, Corynebacterium diphtheriae and B. pertusis.

This powder could protect mice from infection of Pneumococcus, for example, with the injection of $2 \mathrm{mg}$, mice could resist the infection of 10,000 M. L، D.

The toxicity of this powder was extremely small, the subcutaneous injection of $10 \mathrm{mg}$ into mice showed none of the harmful effects.

Also in the human cases the purified powder could be injected intravenously without particular reactions, although the culture fluid or the buffer solution from the first ether extract caused a severe febrile reaction.

Many cases of pneumonia were cured by this substance with daily injection of $200 \mathrm{mg}$ calcium salt (from No. 176 strain). Almost all cases became subfebrile in 24 hours.

\section{Vİ. Probable identity with penicillin.}

On the basis of the following facts it was decided that the antibacterial substance here obtained is identical with penicillin.

1) They are produced by $P$. notatum Westling.

2) The active element is extracted with ether at pH 2.0 and again goes into the water layer at $\mathrm{pH}$ 7.0. It agrees with Raistrick's description.

3) The toxicity of the culture fluid or the purified powder is extremely small against mice as Fleming (3) and recently Chain and others (4) have described.

4) The purified powder is extraordinarily bacteriostatic against Staphylccoccus, Streptococcus, 'Pneumococcus, B. anthracis, C. diphtheriae, but not against B. typhi, B. dysen. teriae, $B$. coli and $B$. pertusis. It agrees with the descriptions by Fleming and Chain.

5) The chemical properties (elemental analysis, absorption maximum, colour reactions) agree with the description by Catch, Cook and Heilbron.

\section{REFERENCES}

1) P. W. Clutterbuck, R. Lovell, H. Raistrick, Biochem. J., 26, 1901, 1932.

2) Catch, Cook and Heilbron, cited in the Review by Kiese. Klin. Wochenschr, 22 45, 1943.

3) A. Fleming, Brit. J. Exp. Path., 10, 276, 1929.

4) E. Chain, H. W. Florey, A. D. Gardner, N. G. Heatley, M. A. Jennings, J. Orr-Ewing, A. G. Sanders, Lancet, 239, 266, 1940. 